\title{
AS DINÂMICAS TERRITORIAIS DO CAPITAL AGRÍCOLA NA AMAZÔNIA E RESISTÊNCIA CAMPESINA: OS DIFERENTES USOS DO TERRITÓRIO NA COMUNIDADE AÇAIZAL EM SANTARÉM - PARÁ
}

\author{
Barbara Eleonora Santos Texeira ${ }^{1}$ \\ Ademir Terra $^{2}$ \\ José Antonio Herrera ${ }^{3}$
}

\begin{abstract}
Resumo: A região de Santarém, no Estado do Pará, sofre com a expansão do capital agrícola da soja, devido a um conjunto de ações públicas e privadas voltado para a agroindústria, com vista à exportação da commodity. Esse conjunto de ações se reflete nos diferentes usos do território, por camponeses e sojicultores, que passam a disputá-lo e, consequentemente, entram em conflito. $\mathrm{O}$ conceito de etnogênese foi empregado como importante instrumento analítico para compreender essa problemática, que envolve distintos interesses e estratégias de uso do território e dos recursos naturais, bem como todas as ações e dinâmicas territoriais, entre elas o processo de resistência campesina em uma das comunidades em conflito no planalto santareno, a Comunidade Açaizal, na qual constatou-se que a disputa não se dá apenas pelo direito de uso da terra, mas também pela preservação de um modo de vida.
\end{abstract}

Palavras-chave: Território. Resistência. Etnogênese.

\section{THE TERRITORIAL DYNAMICS OF AGRICULTURAL CAPITAL IN THE AMAZON AND PEASANT RESISTANCE: THE DIFFERENT USES OF THE TERRITORY IN COMUNIDADE AÇAIZAL EM SANTARÉM - PARÁ}

\begin{abstract}
The region of Santarém, in the State of Pará, suffers from the expansion of the agricultural capital of soybeans, due to a series of public and private actions aimed at the agroindustry, with a view to exporting the commodity. This set of actions is reflected in the different uses of the territory, by peasants and sojicultores, that start to dispute it and, consequently, they come into conflict. The concept of ethnogenesis has been used as an important analytical tool to understand this problem, which involves different interests and strategies for the use of the territory and natural resources, as well as all territorial actions and dynamics, among them the process of peasant resistance in one of the communities in conflict in the Santaren plateau, the Açaizal Community, in which it was verified that the dispute is not only for the right to use the land, but also for the preservation of a way of life.
\end{abstract}

Keywords: Territory. Resistance. Ethnogenesis.

\footnotetext{
${ }^{1}$ Mestranda em Geografia pela Universidade Federal do Pará - UFPA. Email: barbara.eleonora.s.teixeira@gmail.com

${ }^{2}$ Doutorado em Geografia pela Universidade Estadual Paulista Júlio de Mesquita Filho (2009). Email: ademir.terra@terra.com.br

${ }^{3}$ Professor Adjunto IV da Universidade Federal do Pará, na Faculdade de Geografia no Campus Universitário de Altamira e está vinculado como professor permanente no Programa de Pós-graduação em Geografia - PPGEO / IFCH / UFPA - Campus Universitário de Belém. Email: herrera@ufpa.br
} 


\title{
LAS DINÁMICAS TERRITORIALES DEL CAPITAL AGRÍCOLA EN LA AMAZONIA Y RESISTENCIA CAMPESINA: LOS DIFERENTES USOS DEL TERRITORIO LA COMUNIDADE AÇAIZAL EM SANTARÉM - PARÁ
}

\begin{abstract}
Resumen: La región de Santarém, en el Estado de Pará, sufre con la expansión del capital agrícola de la soja, debido a un conjunto de acciones públicas y privadas orientadas a la agroindustria, con vistas a la exportación de la commodity. Este conjunto de acciones se refleja en los diferentes usos del territorio, por campesinos y sojicultores, que pasan a disputarlo y, consecuentemente, entran en conflicto. El concepto de etnogénesis fue empleado como importante instrumento analítico para comprender esta problemática, que involucra distintos intereses y estrategias de uso del territorio y de los recursos naturales, así como todas las acciones y dinámicas territoriales, entre ellas el proceso de resistencia campesina en una de las comunidades en conflicto en la meseta santarena, la Comunidad Acaizal, en la que se constató que la disputa no se da sólo por el derecho de uso de la tierra, sino también por la preservación de un modo de vida.
\end{abstract}

Palabras clave: Territorio. Resistência. Etnogénesis.

\section{Introdução}

Localizado às margens dos rios Amazonas e Tapajós, o município de Santarém tornou-se um ponto estratégico para o escoamento de produtos agrícolas, principalmente da soja, atraindo produtores de diversas regiões do país. Tal localização, associada a uma extensa área de planalto, suscitou a instalação do porto graneleiro da Cargill ${ }^{4}$, o que provocou o aquecimento do mercado de terras e atraiu para a região novos produtores de soja que passaram a compor a vizinhança das comunidades camponesas, entre elas a Comunidade Açaizal, objeto de análise deste estudo. Como consequência, começaram a ocorrer conflitos pela forma de uso e apropriação do território dos camponeses, que impõem resistência à territorialidade do agronegócio, em face das profundas alterações promovidas por ela na natureza.

Por desconsiderar, portanto, o modo preexistente de organização camponesa do espaço, o projeto de expansão de commodities na Amazônia torna-se um vetor de conflitos. A partir dessa premissa, levantamos os seguintes questionamentos: como se dá a resistência camponesa? Quais são seus instrumentos da luta? Como atuam os órgãos oficiais, das diferentes esferas de governo, para dirimir os conflitos territoriais que insurgem e acirram a conflagração já existente na Amazônia, de modo particular na Comunidade Açaizal, objeto da presente análise?

\footnotetext{
${ }^{4}$ Empresa privada, multinacional, com sede no estado de Minnesota, EUA e presente nos cinco continentes, cuja
} atividade é a produção e o processamento de alimentos. 
A pesquisa iniciou-se em 2012, quando, ainda durante a graduação, nos inserimos como pesquisador voluntário no Projeto Cartografia Social, desenvolvido pela Universidade Federal do Oeste do Pará - UFOPA. Seu objetivo era oferecer orientação cartográfica às populações que necessitavam delimitar seu território, mas não possuíam conhecimento para a realização desse trabalho, capacitando os comunitários a empregar técnicas de geoprocessamento para a produção de croquis e mapas sociais. Já desenvolvíamos estudos a respeito da problemática da expansão da soja no planalto santareno e suas consequências. $\mathrm{Na}$ ocasião, os camponeses da Comunidade Açaizal relatavam a ocorrência de conflitos com os representantes do agronegócio que adquiriam terra nas vizinhanças, inclusive dos camponeses da região e até mesmo de membros da Comunidade, expandindo-se, assim, sobre as áreas de uso comum dos comunitários e trazendo, como resultado, graves problemas socioambientais.

Iniciamos uma aproximação com as lideranças da Comunidade, mediada pelo Cacique Josenildo, que nos inteirou dos principais problemas que a afligiam, com destaque para a luta pelo reconhecimento da área como território indígena. O processo de reconhecimento étnico que pleiteavam representa uma das várias formas de resistência camponesa no espaço agrário santareno da atualidade.

Realizamos, primeiramente, uma pesquisa exploratória, visando ao levantamento de informações preliminares junto a alguns comunitários e suas lideranças, para subsidiar a elaboração de um pré-projeto. Como instrumentos de pesquisa, elaboramos, com base nos dados levantados, um questionário e um roteiro de entrevista semiestruturada para subsidiar o trabalho de campo, posteriormente descrito em artigo que foi publicado e apresentado no XXI Encontro Nacional de Geografia Agrária - ENGA, em Uberlândia - MG, em 2012. No ano seguinte, prosseguimos com as atividades de campo e o aprofundamento das análises, dos quais resultou um segundo artigo, publicado e apresentado no VI Simpósio Internacional de Geografia Agrária, realizado em João Pessoa - PB. Avançamos ainda mais nas pesquisas de campo com a Comunidade, a fim de acompanhar o processo de autorreconhecimento, bem como as negociações com as comunidades quilombolas vizinhas que também passavam pelo mesmo processo, mas com interesses divergentes sobre uma mesma área. Além disso, havia o conflito com os sojicultores que adquiriram terra no interior da Comunidade, estabelecendo lavouras muito perto das casas e do principal manancial que abastece os camponeses. $\mathrm{O}$ principal produto científico desses estudos foi a elaboração do trabalho de conclusão do curso 
de Geografia, em 2014, pela Universidade Federal do Oeste do Pará.

O estudo dessas dinâmicas territoriais é fundamental para compreender o processo de desenvolvimento territorial que vem se constituindo na Amazônia ao longo dos anos. As políticas que visam desenvolver o território nacional por meio da produção/extração de commodities desencadeiam diversas formas de resistência das populações locais, como é o caso do recorte espacial aqui analisado, no qual os comunitários empreenderam um movimento com vistas ao fortalecimento de sua identidade territorial, em defesa de seu modo de vida e do meio ambiente, e pela manutenção e permanência na terra.

Em face dos conflitos socioambientais decorrentes da nova dinâmica territorial, envolvendo uso, manutenção e apropriação do território onde estão instalados dois modos de vidas antagônicos, os camponeses buscam estratégias de resistência, entre elas a delimitação e o reconhecimento da área em que vivem como território indígena, ou seja, por meio da etnogênese, nos moldes do que foi estabelecido por Leroy (2009). Tal luta emerge, portanto, em razão das ações e da expansão do capital agrícola, cujos representantes são atraídos para o município de Santarém - Pará, por sua localização geográfica e as facilidades que apresenta, como o asfaltamento da BR-163 (Santarém-Cuiabá) e a estrutura de escoamento de grãos através do porto da multinacional Cargill, instalado em 2003.

Fundamentados nessas premissas, propomo-nos analisar as mais recentes formas de resistência camponesa na região de Santarém, no Pará, a partir dos movimentos de etnogênese que se desencadeiam no território, como estratégia para garantir o direito à terra, frente a expansão das grandes propriedades de monocultura da soja.

A natureza desta pesquisa é de caráter analítico, com fundamentação no método dialético, por entendermos que ele compreende a problemática em sua complexidade social, política, econômica e cultural. Optamos por utilizar teoricamente as categorias conceituais território e camponês, visto proporcionarem uma discussão mais concisa acerca das relações de poder e, principalmente, apresentarem uma carga política ideológica no contexto da expansão do capital agrícola na Amazônia. Metodologicamente, empregamos, a princípio, a pesquisa bibliográfica, tendo por base periódicos, livros e outras fontes, respaldando-nos em autores que discutem território, campesinato e questão agrária, no contexto da expansão agrícola na Amazônia, ou mesmo naqueles que, embora não analisem especificamente a região, desenvolvem estudos que podem contribuir para a compreensão desse espaço. Em 
pesquisa de campo, visando à obtenção de dados primários, realizamos entrevistas semiestruturadas com quinze camponeses na Comunidade Açaizal, entre os quais algumas lideranças, assim como com representantes do Sindicato dos Trabalhadores Rural de Santarém e da Comissão Pastoral da Terra. Todo esse material, por fim, foi empregado para o desenvolvimento da análise proposta.

O texto compõe-se de cinco partes, incluindo esta, na qual buscamos brevemente apresentar o presente trabalho e o percurso metodológico desenvolvido, seguida da seção em que são apresentadas a localização geográfica, bem como as características socioespaciais da Comunidade Açaizal, recorte espacial escolhido para a realização da pesquisa. Na terceira parte, buscamos chamar atenção para as conflitualidades e os diferentes usos do território na Comunidade Açaizal, evidenciando suas contradições e dilemas na manutenção do campesinato frente ao avanço da agricultura capitalista. Na sequência, discutimos a etnogênese, um importante instrumento analítico para a apreensão do processo de resistência campesina. Na quinta e última parte, apresentamos as considerações finais, onde reafirmamos a importância da análise da territorialização do capital na Amazônia como elemento fundamental para a compreensão dos conflitos e das dinâmicas atuais que envolvem dois diferentes sistemas: o agronegócio e o campesinato.

\section{Comunidade Açaizal - localização e contexto socioespacial}

Localizada a $42 \mathrm{~km}$ da sede do município de Santarém, no Pará (Figura 1), a Comunidade Açaizal, a que se chega pela rodovia estadual PA-370, Santarém/Curuá-Una, e, posteriormente, seguindo por alguns ramais de comunidades quilombolas e aldeias vizinhas. Possui solo argiloso, vegetação do tipo "capoeira" e um igarapé no seu entorno, que passa por um processo - perceptível - de assoreamento e também, segundo relato dos camponeses, de contaminação resultante do cultivo de soja. Apesar de os comunitários comporem um conjunto de quatro aldeias (Açaizal, Ipaupixuna, São Francisco da Cavada e Amparador) e se autoidentificarem como indígenas Munduruku do Planalto (isto porque o povo Munduruku habita outras áreas em Santarém, havendo, inclusive, aldeias próximas localizadas na Floresta Nacional do Tapajós, em processo de demarcação), o processo de autorreconhecimento só teve início a partir de 2004, em decorrência dos conflitos que se sublevaram no território.

As 54 famílias que compunham a aldeia até 2014 são constituídas por 
descendentes de indígenas da região e por migrantes nordestinos que nela se estabeleceram, atraídos, principalmente, por políticas governamentais implantadas a partir da década de 1960 pelos governos militares. Para essas famílias, o cultivo da terra e o extrativismo são fundamentais para o seu sustento e reprodução social como camponeses, uma vez que, para eles, as relações entre trabalho e família são indissociáveis, ou seja, dependem essencialmente do uso dos recursos naturais que advêm da terra e da floresta, como forma de produção e reprodução do seu modo de vida. "No campesinato é impossível separar a prática econômica da família. As duas coisas estão ligadas de forma distinta daquela que se dá, por exemplo, numa família de classe média no meio urbano" (MOURA, 1988, p. 26). 


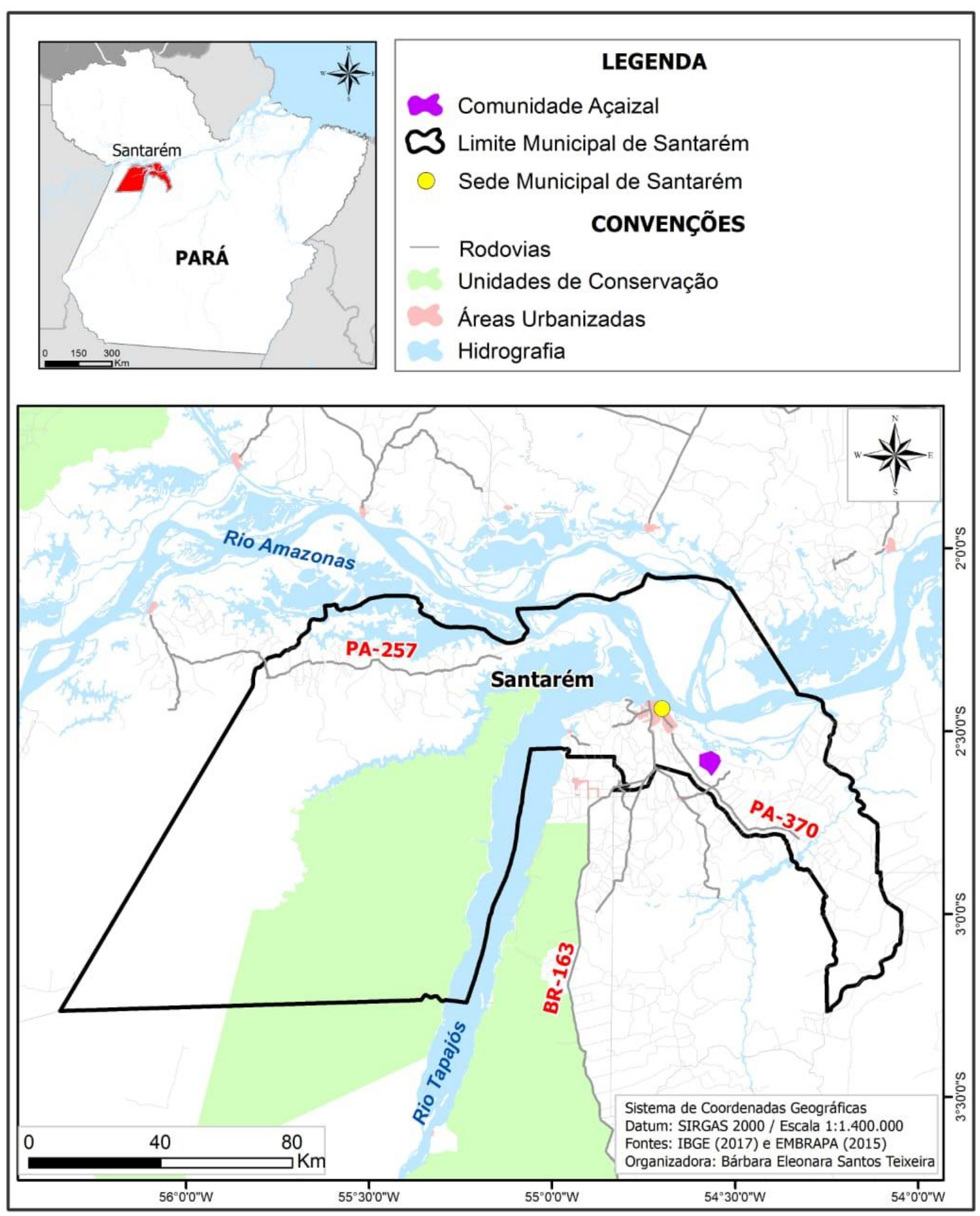

Figura 1 - Localização geográfica da Comunidade Açaizal

Até o ano de 2004, a Comunidade Açaizal era uma comunidade amazônica típica, como tantas outras na região. Todavia, esse panorama começou a mudar quando outras 
comunidades iniciaram um movimento de reivindicação de identidade, como estratégia de enfrentamento e resistência frente às ações do capital em seus territórios (madeireiros, fazendeiros, sojicultores, grileiros). Os camponeses da vizinha Comunidade de Tiningú, por exemplo, que se autodenomina quilombola, tentam convencer outras comunidades da vizinhança a aderir ao processo de aquilombamento. Nesse contexto, emergiu uma disputa entre os camponeses da Comunidade de Tiningú e da Comunidade Açaizal, uma vez que os componentes desta não se reconhecem como quilombolas e, consequentemente, não aceitam a incorporação de seu território ao dos das demais comunidades, o que é uma demanda do processo de demarcação quilombola. Justificando a opção pelo autorreconhecimento de sua comunidade como indígena, e a resistência à adoção da identidade quilombola, bem como indicando o marco da gênese dessa disputa, uma moradora da Comunidade Açaizal deu a seguinte declaração:

Eu passei a me reconhecer como indígena desde 2004, porque foi quando a gente foi acordar! Porque naquela época, o Tiningú, que é a comunidade vizinha ali, que é quilombola, eles fizeram uma reunião lá e queriam colocar todas as comunidades como quilombola, e nós vimos que nós não nos identificamos como quilombo, né!? Então nós reunimos a comunidade e optamos por fazer a nossa associação indígena e passar o nos reconhecer como indígena, porque desde o início dos tempos quem ocupou a terra foram os indígenas, e os quilombola não são daqui da nossa terra! Já vieram, que são os africanos, eles vieram da África para cá. (Moradora, 2014)

Segundo Peixoto (2011), na Floresta Nacional do Tapajós - Flona Tapajós, o movimento indígena de reivindicação de identidade e território teria iniciado em 1998, quando uma comunidade declarou-se Munduruku ${ }^{5}$. Logo outras comunidades ao longo do rio Arapiúns e no Baixo Tapajós também se assumiram indígenas, e o movimento ganhou intensidade, com a adesão de dezenas de aldeias, que se filiaram ao Conselho Indígena Tapajós-Arapiúns - CITA. Na gênese do movimento, encontra-se o Grupo de Consciência Indígena - GCI, fundado em 1997, o qual, juntamente com o CITA, tem negociado com a FUNAI a realização de estudos de identificação e delimitação territorial.

São esses agentes que mobilizam e orientam as comunidades a resgatarem sua identidade e se autoafirmarem como determinado grupo étnico. Este fenômeno pode ser

${ }^{5}$ Existem atualmente cerca de 10 mil índios Munduruku, nos estados do Pará (alto, médio e baixo rio Tapajós) e Amazonas (rio Madeira). Com mais de dois séculos de contato com os não indígenas, grande parte da população é bilíngue, mas há falantes monolíngues tanto em Munduruku quanto em Português (COSTA; GOMES, 2011). 
entendido por meio da ausência ou negação de seus direitos (PEIXOTO, 2011). É assim que essas populações, com características próprias do modo de vida camponês, desenvolvem no seu cotidiano ações de resistência às desapropriações e à violação de seus direitos, visando à manutenção de sua cultura e de seu modo de vida, por meio da luta contra a grilagem de suas terras, as invasões das madeireiras, a caça predatória e demais investidas de forasteiros em seus territórios.

A partir do momento em que esses grupos afirmam sua identidade étnica, passam a ser vistos com mais ênfase pela sociedade e pelo Estado, em seus diferentes níveis de governança. No entanto, essa ainda é uma longa e árdua batalha, pois, mesmo que tenham reconhecida sua identidade étnica, tais populações ainda sofrem em razão da ausência do Estado e da precariedade dos serviços básicos, como educação, saúde, saneamento etc., situação que prevalece nas diversas regiões brasileiras (PEIXOTO, 2011).

Atualmente, uma das maiores preocupações dos moradores da Comunidade Açaizal é a expansão do cultivo de soja em seu território. Os conflitos iniciaram por volta do ano de 2009, quando passou a ser alvo da cobiça dos sojicultores. Estes novos atores sociais, além de se apropriarem dos territórios, com a compra e a venda da terra, desterritorializam e produzem novas dinâmicas, promovendo conflitos socioambientais pela apropriação e uso do território indígena.

\section{As conflitualidades e os diferentes usos do território na Comunidade Açaizal}

Historicamente, a luta pela propriedade da terra é a principal questão norteadora dos conflitos socioterritoriais que afligem toda a região amazônica, onde, nas últimas décadas, eles se tornaram mais complexos e ganharam novos contornos, a partir da introdução das lavouras de commodities. O recorte espacial aqui analisado não ficou imune a essa problemática, como evidencia o relato do senhor Juvenal (um dos comunitários):

Nós tínhamos uma área de terra aqui atrás, de nove hectares, que era da comunidade, o dia que a comunidade precisava de uma madeira ou colher fruto (castanha), ia lá. Só que lá tinha muita madeira e isso despertou interesse de outras pessoas. Um dia a gente precisou de madeira para construir uma igreja, e fomos lá tirar a madeira, uma árvore era suficiente para construir, então no outro dia fomos lá para dividir as toras. Aí foi uma confusão porque o sojeiro se alterou e bateu o tessado (facão) lá e disse que a terra era dele! Eu falei a ele que morava aqui há quarenta anos e sempre tomei conta dessa área de terra, e conheço essa mata como a palma de minha mão, e essa área de terra é da comunidade há anos, foi quando ele 
falou que comprou do INCRA e que deu $R \$ 12.000$, e ia denunciar a gente, nós respondemos que quem ia fazer a denúncia éramos nós, fomos para o INCRA, Ministério Público, mas não deu em nada. (Morador, 2014)

A maioria dos moradores da Comunidade Açaizal não possui título de propriedade da terra, tendo em vista que a posse precária é uma característica intrínseca aos povos indígenas e aos camponeses da região. São, portando, posseiros, e a posse dos seus territórios é transmitida hereditariamente de geração em geração entre os comunitários. Oliveira (1989) afirma que os povos indígenas têm assistido ao "encolhimento" de seus territórios, a princípio, pela entrada de posseiros e, depois, pelo "grilo" dos grandes grupos econômicos capitalistas. Tal situação pode ser verificada na Comunidade, posto que a sua população resultou de uma integração intercultural dos indígenas que habitavam a área com posseiros oriundos do Nordeste brasileiro.

Além de terem que viver cotidianamente na iminência de serem expropriados de seu território, os indígenas e camponeses da Comunidade Açaizal veem o seu modo de vida tradicional ameaçado, uma vez que, compulsoriamente, têm que se sujeitar à convivência com a lógica do agronegócio no mesmo território, com territorialidades diferenciadas, que causam mudanças naturais e sociais em seu modo de organização, uma vez que o avanço do capital não considera as idiossincrasias e especificidades indígenas e camponesas.

O capital agrário sempre esteve presente no território, pois as relações de subordinação da produção camponesa fazem parte da história de exploração da Amazônia. A Comunidade Açaizal, ao longo dos anos, enfrenta as diversas formas de capital agrícola, principalmente após a abertura das novas rodovias e da implementação dos grandes projetos de desenvolvimento agropecuário na região, que absorveram extensas áreas de terra e força de trabalho da população das comunidades em seu entorno, deixando uma herança de áreas desmatadas, classificadas hoje como floresta secundária, ou capoeira. $\mathrm{Na}$ Comunidade pesquisada, essas fazendas empregavam parte dos moradores, que trabalhavam como vaqueiros, isto é, as fazendas exploravam o trabalho dos camponeses que habitavam a região ao longo de várias gerações, como relata o senhor Juvenal:

Antes eu trabalhava como vaqueiro capataz de fazenda, e quando eu nasci, meu pai já trabalhava com fazenda, e eu segui nessa profissão. Trabalhei com fazenda 35 anos, só parei de trabalhar como vaqueiro quando a

${ }^{6}$ Entrevista realizada no dia 16 de maio de 2014 com o senhor Juvenal da Silva Coelho, 73 anos, morador da 
fazenda foi vendida para os sojeiros. A terra que eu tenho e moro foi doada pelo meu antigo patrão, eu pedi um pedaço de terra para fazer minha casa, ele me mandou escolher onde eu queria, e eu escolhi. E depois ele vendeu a área que me deu, por que era mais valorizada, depois me deu outra área onde fiz minha casinha. Eu tenho um título de Imposto Territorial Rural, a doutora me disse "olha, cadastra tua terra por que esse pessoal de fora não é igual nós, e um dia eles podem te "aperrear" (pressionar) por conta da tua terra"; agora eu pago $R \$ 40,00$ reais todo ano pela minha terra. (Morador, 2014)

Oliveira (2012) explica que os capitalistas se utilizam das relações de trabalho familiar para não terem que investir na contratação de mão de obra assalariada, sendo que o fruto do trabalho camponês (proprietário, parceiros, rendeiros ou posseiros) é convertido em mercadoria e, quando vendida, converte-se em dinheiro. Esse processo nada mais é do que o da produção do capital, que se faz por meio das relações não capitalistas.

A produção agropecuária no Brasil contém as contradições inerentes à lógica do desenvolvimento capitalista no país. Esse processo geral marcado pela concentração de terra nos latifúndios e pela expansão da unidade camponesa, aparece sobretudo mascarada pelos diferentes usos a que a terra está submetida. Um exemplo expressivo da maquiagem do processo de concentração da terra está na distribuição do uso do solo pelas atividades agropecuárias. Os dados referentes ao uso da terra, segundo os grupos da área, demostram que ao se comparar a realidade do campo, entre 1940 e 1985 verifica-se que em termos globais, o Brasil tem mais de $45 \%$ de suas terras ocupadas por pastagens, que tem sido a forma de uso mais comum para "esconder" a terra mercadoria - reserva de valor - à espera da especulação imobiliária. (OLIVEIRA, 2012, p. 87)

Evidencia-se, assim, o processo de especulação que ocorreu nas terras do planalto santareno, principalmente na Comunidade Açaizal: as fazendas que existiam na área concentravam grandes extensões de terras e, mesmo com a queda da produção bovina, os proprietários as mantiveram como garantia de sua propriedade, e mais ainda, como especulação imobiliária. Com a introdução do cultivo da soja na Amazônia, essas terras se tornaram supervalorizadas, uma vez que essa lavoura, teoricamente, só poderia ser cultivada na região em áreas degradadas, principalmente pela pecuária (GAYOSO DA COSTA, 2015).

Nesse contexto, as fazendas (que empregavam parte dos moradores) localizadas na Comunidade Açaizal passaram a dar lugar à soja. Disso resultou a reorganização do território camponês, que teve sua dinâmica de reprodução modificada, não havendo mais lugar para a relação de subordinação ou trabalho assalariado antes existente. Os novos agentes que se 
instalaram no território, com sua produção mecanizada, não tinham interesse em participar da vida social daquele grupo. Até aí, o sentimento dos moradores era de descontentamento, pois, além de não conseguirem compreender as relações puramente comerciais que os novos agentes desenvolvem com a terra, tampouco viam perspectivas de reprodução de seu modo de vida. As relações, no entanto, começaram a se tornar conflitantes, a partir do momento em que os sojicultores passaram a se apropriar dos recursos naturais de que os habitantes desse território outrora dispunham e a degradá-los. Tal assertiva é corroborada com o depoimento do senhor Juvenal:

Nós entramos em conflito com os sojeiros, porque não tão deixando nós trabalhar, tá sufocando nós! Porque de primeiro, todos nós éramos só um tipo de pessoa. Nós podia passar pelo terreno um do outro, pra caçar, pra procurar boia pra nós, (ninguém vive de caçar, mas a gente caça pra comer e não para comerciar) e hoje você não pode criar um carneiro, um porco, uma galinha, porque os sojeiros colocam veneno no plantio deles e mata nossa criação! Acabou com nosso igarapé, nem banhos nós toma mais lá, foi preciso nós mandar cavar poço, porque dá coceira no pessoal, porque a água tá cheia de veneno, já vieram fazer uma pesquisa, porque tem suspeitas que a água tá envenenada, o peixe tá envenenado, e mandaram a gente não consumir nada do igarapé por segurança. (Morador, 2014)

O depoimento do senhor Juvenal traz à tona outro motivo de conflito entre o campesinato e a agricultura comercial na Comunidade Açaizal: a questão do desmatamento da mata ciliar e da possível contaminação da água do igarapé que abastece sua população. Segundo os moradores, ali costumavam pescar e praticar o extrativismo, além de realizar atividades de lazer, práticas que foram suprimidas, porém, pela grande quantidade de agrotóxicos e fertilizantes despejada no leito dos igarapés pelo processo de escoamento superficial e sedimentar que ocasiona o assoreamento, já que as plantações de soja são submetidas constantemente ao controle de pragas, com a utilização de pesticidas.

Nós tem um igarapé que é a cabeceira de todos os igarapés que abastecem as outras comunidades vizinhas. Só que ele tá acabando, por causa do desmatamento e da plantação de soja, porque quando chove, a enxurrada leva aquela terra para o igarapé, aí vai aterrando cada vez mais; a água não é mais limpa, é barrenta, "velha". Hoje em dia, quase ninguém está usando a água do igarapé, porque é uma água contaminada, nossos filhos não sabem o que é se jogar em uma água de igarapé como nós fazia quando era criança, porque a água não presta mais nem para tomar banho. Muitos de nós começaram a cavar poço, ou usar a água do poço do vizinho. Mas daqui um tempo nem a água do poço vai prestar mais, porque do jeito que 
tá, nem a água do poço vai prestar mais. E aí, como nós vamos sobreviver sem água? (Morador, 2014) ${ }^{7}$

Empiricamente, os camponeses têm consciência de que muitos dos problemas que os afligem na atualidade decorrem da territorialização e espacialização do cultivo da soja, principalmente no que concerne aos problemas ambientais. O desmatamento e o plantio em larga escala eliminam a cobertura vegetal do solo, fazendo com que o escoamento das águas pluviais leve consigo a proteção natural, provocando erosões e o consequente assoreamento, assim como a poluição dos mananciais da Comunidade. Em virtude da utilização de grandes quantidades de produtos químicos (agrotóxicos) no plantio da soja, além dos danos ao meio ambiente, também a saúde humana é prejudicada, especialmente daqueles que a eles estão expostos diretamente, como os moradores das comunidades localizadas no entorno das áreas cultivadas.

Todas essas questões estão diretamente relacionadas às diferentes formas de utilização dos diversos recursos naturais de um território disputado por atores sociais que possuem interesses socioeconômicos e valores socioculturais antagônicos. O modo como os moradores da Comunidade Açaizal usam a natureza é considerado pelos sojicultores como atrasado e antieconômico. Todavia, enquanto os camponeses veem a floresta como um organismo vivo a ser preservado, fonte permanente de recursos dos quais retiram seu sustendo para a manutenção do seu gênero de vida, para os sojicultores, a floresta ou mata é percebida como uma fonte de recursos a serem explorados imediatamente, com vista a abrir espaço para o cultivo de lavouras comerciais.

Sendo assim, é possível compreender a conflitualidade que se estabelece no território onde, de modo paradoxal, como aponta Fernandes (2010), ocorrem, concomitantemente, a territorialização, a desterritorialização e a reterritorialização de diferentes relações sociais. A ocorrência desses processos geográficos gerados pelo conflito é mais bem compreendida quando analisada nas suas temporalidades e espacialidades. São processos de desenvolvimento territorial rural formadores de diferentes organizações sociais.

Nesse contexto, a oposição entre dominantes e dominados, entre opressores e oprimidos, onde o camponês é quase sempre vítima em qualquer tempo e lugar, sua posição é marcada pela subordinação (MOURA, 1988). Evidencia-se que na Comunidade de Açaizal

${ }^{7}$ Entrevista realizada em 16 de maio de 2014 com o senhor Juvenal da Silva Coelho, 73 anos, morador da Comunidade Açaizal. 
essas relações paradoxais estão presentes desde as mais remotas políticas de desenvolvimento territorial implantadas pelo Estado na Amazônia, como no caso do incentivo à criação bovina no território. No entanto, hoje, elas estão marcadas pelo paradoxo entre o capital agrícola da soja e o modo de vida camponês.

\section{A etnogênese como resultante do processo de resistência indígena}

A Comunidade Açaizal somente se autoafirmou como indígena em 2004, iniciando, assim, o seu processo de etnogênese. Entretanto, os elementos que dão sustentação a tal processo foram sendo construídos ao longo da existência da Comunidade. Seus moradores já detinham o conhecimento de suas origens indígenas, haja vista os rituais, costumes e crenças que compartilham no seu cotidiano, todavia, sem qualquer preocupação em discutir sua identidade. Doravante, nos deteremos a entender as dinâmicas territoriais do capital agrícola nessa Comunidade e, por conseguinte, a forma de resistência dos camponeses frente a esse novo modelo de exploração agrícola, procurando analisar e compreender esse movimento de autorreconhecimento étnico, a que os antropólogos denominam etnogênese.

Florêncio (2001) afirma que esse termo pressupõe a ação de um "grupo étnico que poderia parecer que não estava lá, que se redefine na atualidade criando novas configurações culturais", acompanhadas muitas vezes por demandas por territórios materiais e simbólicos. Para o autor, a etnogênese, em uma perspectiva geográfica, está ligada ao conceito de território, pois este constitui, para as populações, fonte de recursos, ao mesmo tempo, material e simbólica (e área protegida de especial valor ecológico). O reconhecimento do território indígena, interligado ao seu modo de vida e à ancestralidade do uso e ocupação, é uma das consequências da articulação política correspondente à etnogênese, como verificado com os Munduruku do Planalto, segundo os moradores da Comunidade de Açaizal. Ainda de acordo com Florêncio (2001), a necessidade da posse e uso da terra ou a de emergir como um grupo de cidadãos de direitos fazem com que um povo busque formas de ver atendidas suas reinvindicações perante o Estado. Nesse sentido, a etnogênese vai além da retomada das tradições, pois, em face da expansão da soja, que neste caso está associada à degradação ambiental, implica uma reorganização socioespacial de um povo em defesa de seu território, seja na sua forma material em extensão, como se configurou na conflitualidade camponesa, indígena e quilombola na Comunidade Açaizal, seja no que traz de simbólico, como seu modo 
de vida.

Fernandes (2010) afirma que é a partir desse estado de confronto que surge o empate $^{8}$, isto é, a resistência, uma vez que o conflito pode ser enfrentado a partir da conjugação de forças que disputam ideologias para convencer ou derrotar as forças opostas, ou seja, é a partir da ideologia de um grupo que se constrói a base para a resistência de um povo.

Um conflito pode ser "esmagado" ou pode ser resolvido, entretanto a conflitualidade não. Nenhuma força ou poder pode esmagá-la, chaciná-la, massacrá-la. Ela permanece fixada na estrutura da sociedade, em diferentes espaços, aguardando o tempo de volta, das condições políticas de manifestação dos direitos. (FERNANDES, 2010, p. 26)

Com base nas formulações de Fernandes (2010), podemos compreender o processo de resistência que aflora na Comunidade Açaizal. Os conflitos sempre estiveram presentes naquela região, ainda que em tempos sociais e políticos distintos, mas sempre foram superados através da subordinação, como ocorreu com os fazendeiros, ou de forma consensual, como aconteceu com os quilombolas. A conflitualidade, no entanto, permanece no território, surgindo oportunamente quando há a necessidade da luta por direitos, ou de defesa do próprio território, com todas as suas vertentes e significações.

Nesse sentido, a resistência por meio da etnogênese se constitui a partir da conflitualidade entre quilombolas e indígenas na disputa do território, quando os quilombolas tentam instituir sua cultura e modo de vida às outras comunidades, como forma de garantir o território aos seus descendentes, gerando conflito com outro gênero de vida, o indígena. Os camponeses da Comunidade Açaizal, por sua vez, usam a mesma estratégia - a etnogênese para defender o seu território, cientes de que somente com o reconhecimento de suas terras como território indígena poderão resguardá-las. Os então comunitários, a exemplo de outras comunidades camponesas da região, resolveram autoafirmar-se como indígenas e organizar-se em associação para melhor respaldar suas lutas, como relata o primeiro presidente da Associação Indígena da Comunidade:

Surgiu a associação quilombola aí no baixão e nós fomos convidados a participar da associação deles, a gente entendeu que aquilo ia prejudicar a

\footnotetext{
${ }^{8} \mathrm{O}$ termo empate, criado pelos camponeses seringueiros do Acre, significa um resultado de um conflito em que ninguém perde nem ganha. Ao fazerem um empate, impedindo a derrubada de árvores, e têm êxito na empreitada, consideram que nem eles, nem a empresa madeireira perdem ou ganham, pois eles estavam garantindo a permanência na terra e impedindo o desmatamento (FERNANDES, 2010, p. 26).
} 
gente, porque eles enquanto quilombolas queria as terras da nossa região, $e$ nós não concordamos e decidimos fazer uma associação para nós. Nessa época, chegou o frei Alex, que nos aconselhou a fazer uma associação indígena, isso em 2004, então ele junto com a CPT e o Frei Amarildo, nos orientaram como devíamos regularizar a associação. Foram três anos tentando regularizar a associação. Até agora só delimitamos nossa área com a ajuda do Cartografia Social, nós levamos eles lá e mostramos onde era nosso território, nós mesmos ajudamos a fazer os mapas da nossa área, mas a FUNAI ainda não veio aqui iniciar o processo de reconhecimento do nosso território indígena. (Morador, 2014) ${ }^{9}$

Com a ajuda da Comissão Pastoral da Terra - CPT e de outras associações indígenas Munduruku, bem como com o auxílio do Projeto Nova Cartografia ${ }^{10}$, esses camponeses se organizam e promovem constantemente momentos de reflexão e de formação. Inicialmente, fizeram um levantamento histórico da comunidade, a partir de relatos dos moradores mais antigos, que resgatavam histórias contadas pelos seus avós indígenas e camponeses, assim como, costumes e crenças vivenciados por eles em sua infância e que permanecem até hoje, repassados de forma hereditária e consuetudinária. As reuniões de formação tornam-se extremamente importantes, não só como forma de reafirmação de sua cultura, mas também de fortalecimento para enfrentar a discriminação a que são submetidos quando desenvolvem atividade tipicamente multicultural, marcada por características da etnia indígena, que não raramente são consideradas pelos "de fora" como sinônimo de atraso e selvageria, percepção preconceituosa e ignorante, vinculada ao pensamento do colonizador europeu.

Diante do conflito, os moradores têm urgência do reconhecimento legal de suas terras, pois essa é o meio apropriado para alcançarem os seus objetivos de preservação da natureza, sua reprodução como seres sociais, conquista de maior autonomia no território e, por conseguinte, maior respaldo na luta contra as constantes invasões de madeireiros e caçadores, acompanhadas, mais recentemente, da expansão do capital agrícola, principalmente com o cultivo da soja em suas terras.

A chegada dos produtores de soja na Comunidade, a partir de 2008, gerou novos conflitos, tendo em vista que a dinâmica de territorialização desses novos agentes tem como elementos o emprego de pouca mão de obra (Figura 2)- os poucos funcionários contratados

\footnotetext{
${ }^{9}$ Entrevista realizada 16 de maio de 2014 com o senhor Pedro Costa, 55 anos, agricultor e ex-presidente da associação indígena de Açaizal.

${ }^{10}$ O Projeto Nova Cartografia Social da Amazônia ensina indígenas, quilombolas e outros grupos tradicionais a empregar o GPS e técnicas modernas de georreferenciamento para produzir mapas artesanais, mas bastante precisos, de suas próprias terras (Fundo Amazônia, 2018).
} 
são de fora da Comunidade - utilização de grandes extensões de terras, uso de pacotes tecnológicos e de defensivos agrícolas e fertilizantes que, como já citado anteriormente, geram impactos diretos no meio ambiente - desmatamento e contaminação de mananciais acrescidos da proliferação de pragas na produção campesina, majoritariamente orgânica. Toda essa dinâmica se contrapõe ao modo de vida camponês, que tem sua produção baseada no trabalho familiar e voltada à subsistência, como explica o senhor Itaguaí ${ }^{11}$, morador da Comunidade:

Eles (os sojicultores) trabalham com dinheiro do banco e nós trabalhamos com nossa força. Eles têm que ver isso aí. A nossa comunidade sempre trabalhou "braçalmente", nunca ninguém mexeu com trator. A gente faz uma roça esse ano aqui, quando colhemos, isso vira mato de novo e nós vamos fazer em outro canto, assim a gente vai e volta. Daqui a uns cinco anos, esse terreno do gaúcho não tem mais é nada, nem mato vai nascer aí. Porque a nossa terra aqui ó, eu planto capim, então a terra tá sendo protegida. Vá ali e "espie": é veneno, é máquina em cima direto [...] Eles fazem uma área aí de cem hectares e envenenam. O passarinho vai tudo pro meu roçado. Meu roçado é bem pequenininho. Eu plantei dez tarefas e não colhi um quilo! Passarinho foi tudo pra lá porque lá eu não uso veneno. Então depois que ele passou a ser meu vizinho, acabou, não posso mais mexer em roçado. [...] Nasci e me criei vivendo da terra, plantando, criando um boizinho e comendo do mato. Criei meus filhos só caçando. Me "lasquei" trabalhando pros meus filhos não saírem da escola e estou orgulhoso disso porque está dando resultado. (Morador, 2013)

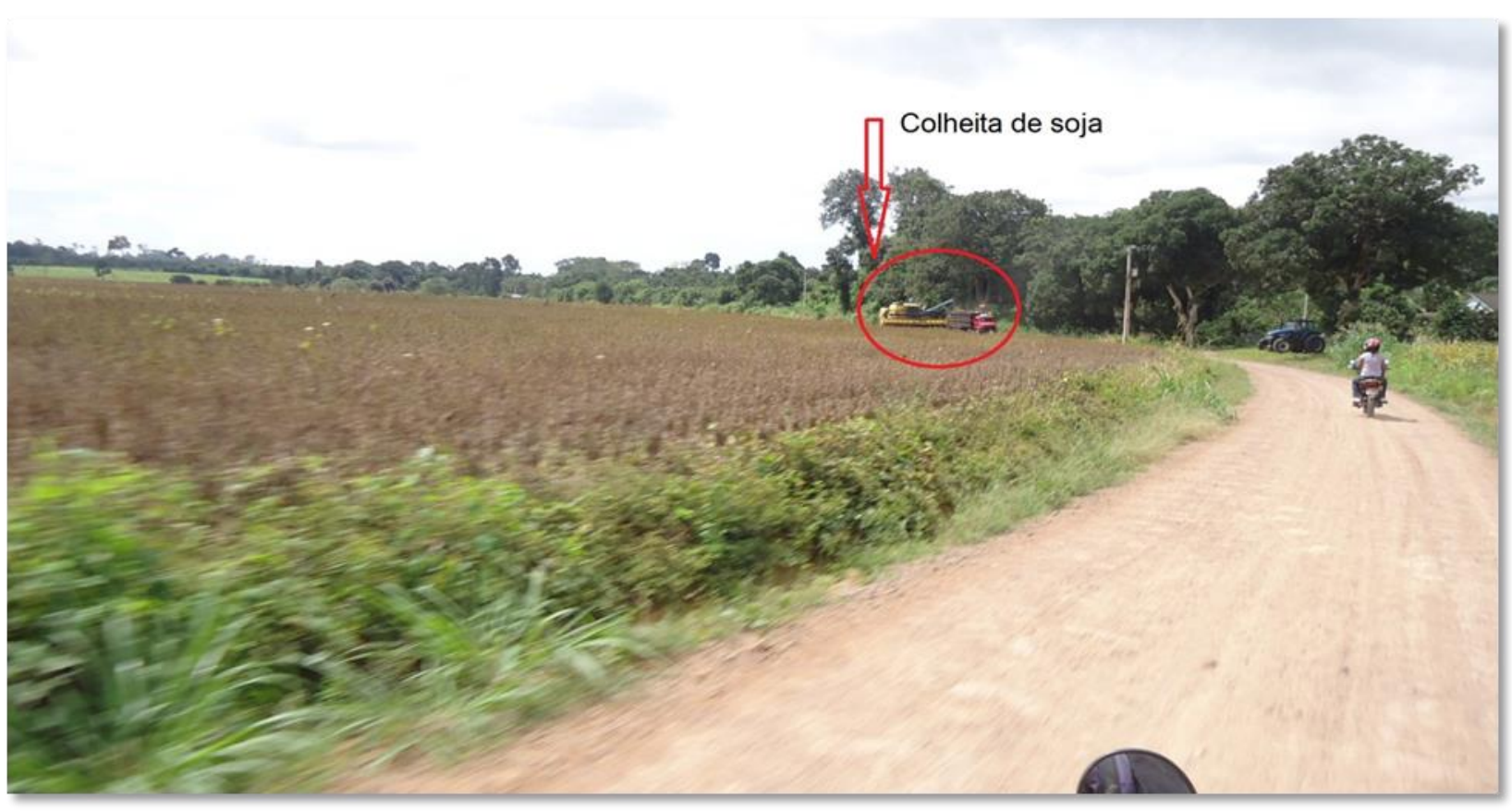

Figura 2 - Colheita de soja

11 Morador da comunidade, de 53 anos. 
Fonte: Autor (2014)

Analisando o funcionamento do mercado de insumos agrícolas, Teubal (2008) explica como ele se conecta a empresas do setor financeiro, formando os denominados pools de semeadura, transformando o setor num negócio financeiro.

As grandes empresas de sementes, unidas com as que vendem os agrotóxicos - cujo consumo cresce consideravelmente no setor - adquirem uma vantagem inusitada no sistema agroindustrial de nosso país, fortalecidas em grande proporção como consequência das denominadas revoluções tecnológicas dos híbridos (a "revolução" verde) e, mais recentemente, a dos transgênicos (a revolução biotecnológica). (TEUBAL, 2008, p. 146)

Os moradores da Comunidade Açaizal, além de cultivar mandioca, milho, feijão e arroz, criam animais, como aves, suínos e bovinos (Figura 3), que são a base da alimentação de seus habitantes. Contudo, a utilização de agrotóxicos nos arredores compromete a criação de animais na localidade, os quais estão sempre em risco de ingerir substâncias nocivas. A possível contaminação do igarapé é também motivo de muita preocupação, pois aqueles que se arriscam a utilizá-lo (famílias que não têm condições de instalar poços artesianos), estão sujeitos a contrair doenças, pois, de acordo com o relatado dos comunitários, nos últimos meses a água do igarapé tem provocado alergias e há suspeitas de que casos recentes de hepatite e aborto, na Comunidade, tenham sido provocados pela ingestão da água contaminada do igarapé. 


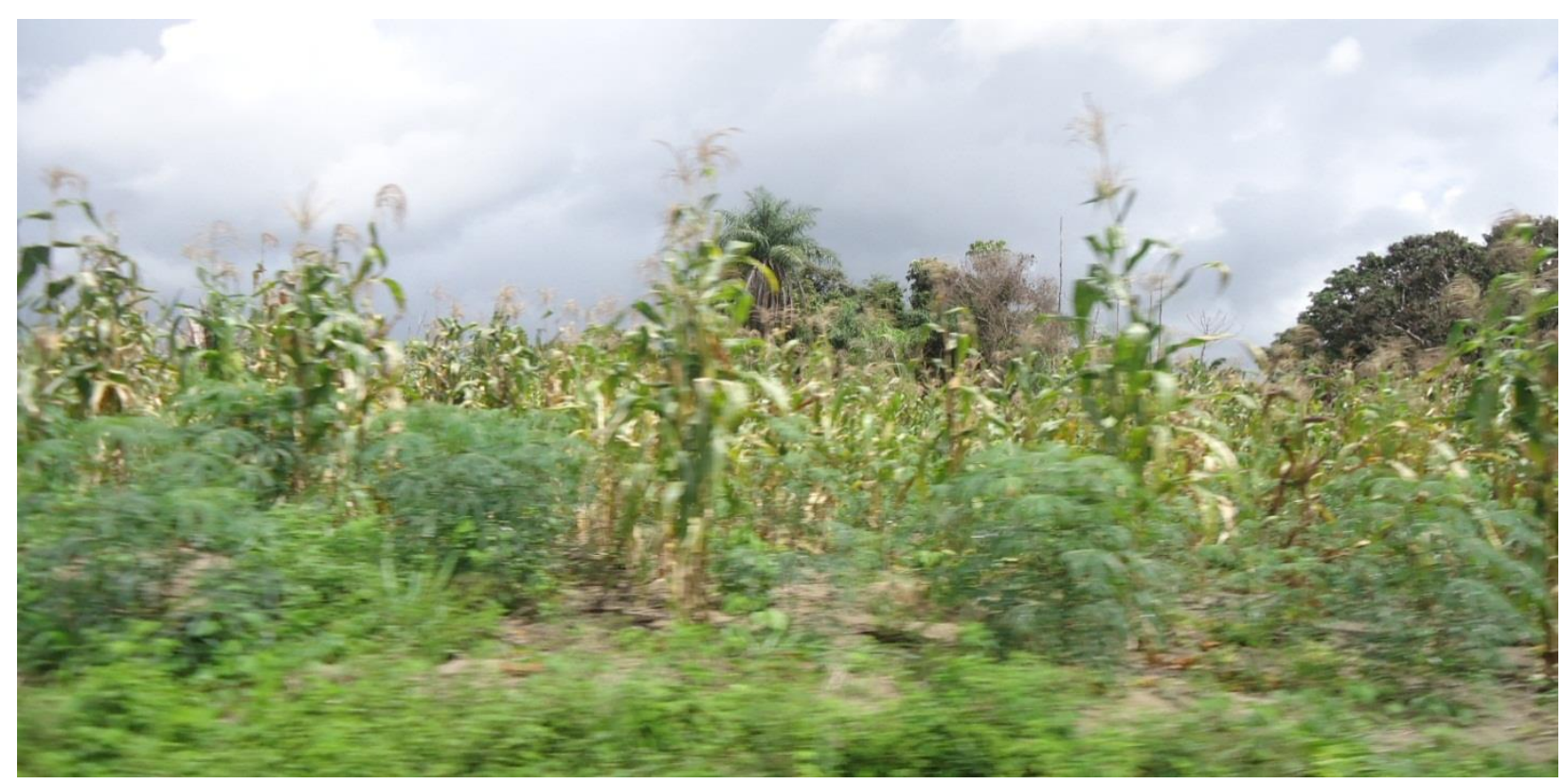

Figura 3 - Plantação de milho e mandioca Fonte: Autor (2014)

Evidencia-se também a elevação do preço das terras na região. Segundo Gayoso (2013), que aponta três características básicas para a formação do mercado de terras - "Terras com Mata", "Terras de Pastagem" e "Terras de Lavoura" - o processo de grilagem de terras desencadeado na região tomou impulso a partir da chegada da soja, quando as áreas com matas serviram como meio de capitalização para a instalação da lavoura de grãos. Observa-se que grande parte do território da Comunidade Açaizal abriga floresta secundária (capoeiras) ou fazendas de pecuária, que atualmente dão lugar a campos de soja, restando poucas áreas de florestas primárias, as quais são alvo de disputa entre sojicultores e camponeses, uma vez que vêm sendo constantemente apropriadas por esses grandes produtores.

Seguramente ligada à territorialização da monocultura da soja na região, desenvolvida por produtores rurais capitalizados oriundos de outras regiões, a intensa capitalização de terras provocou o êxodo rural, fenômeno que se intensificou no planalto santareno a partir de 2003. Muitas famílias camponesas migraram para os municípios da região, acreditando que com os valores alcançados com a venda de suas terras fosse possível estabilizarem-se no meio urbano em condições melhores do que as que tinham no meio rural. Ainda que alguns poucos tenham conseguido êxito, a maioria teve que regressar para as comunidades de origem, em condições mais precárias do que as que detinham antes de partir.

Uns vizinhos nosso venderam seu pedacinho de terra e foram pra cidade, só 
para sofrerem com os filhos. Pois vai pra lá fazer o que? Não tem um bom emprego, não tem estudo. E muitos já morreram por causa de bandidagem. Entrou no mundo do crime, tu sabe como é, né? A vida é curta. Muitos já tentaram voltar e não conseguiram. Os que deixaram família aqui voltaram, agora estão morando um em cima do outro. (Moradora, 2013)

No intuito de evitar tais situações, a Associação Indígena, em parceria com a CPT e o Sindicato dos Trabalhadores Rurais de Santarém - STRS, desenvolveu campanha de conscientização com base no lema "não venda sua terra", a fim de esclarecer a população camponesa sobre as consequências oriundas dessa decisão (Figura 4) .

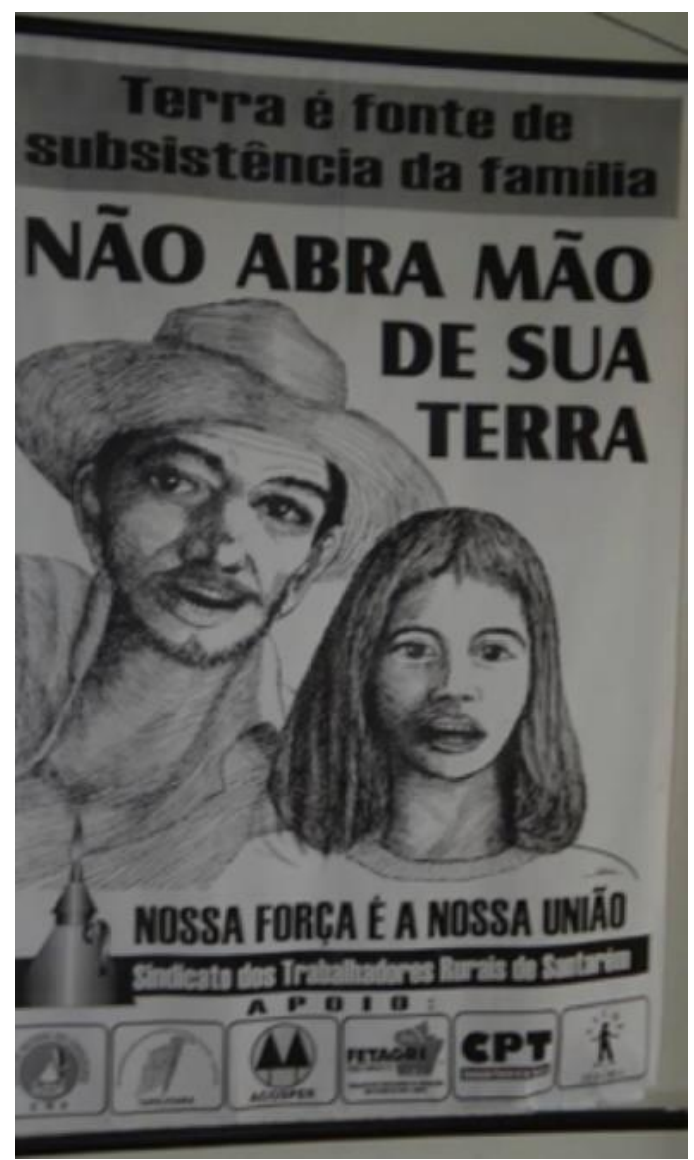

Figura 4 - Cartaz da ampanha "não abra mão de sua terra" Fonte: STRS (2014)

Diante de tal problemática, alguns líderes comunitários (muitos dos entrevistados para a elaboração deste estudo) decidiram procurar o Ministério Público para denunciar, principalmente, a derrubada de castanheiras (considerada crime pelo Decreto ${ }^{\circ} 5.975$ de 30 
de novembro de 2006), assim como os conflitos decorrentes dos dois modos de vida que se desenvolvem de forma antagônica.

Para Fabrini (2007), as relações camponesas são marcadas por certa autonomia e controle do processo produtivo, diferentemente do que ocorre na produção em escala do agronegócio. Embora subordinado, o camponês é conhecedor do processo de produção e, por isso, a alienação que atinge os trabalhadores expropriados não o atinge da mesma forma. É a partir da compreensão do seu estado de exploração e subordinação que o camponês passa à condição de enfrentamento e, por conseguinte, de resistência. O espaço de luta e resistência é também um importante espaço de socialização política, durante a formação do movimento. "É a manifestação pública dos sujeitos e de seus objetivos. É efetivamente o espaço de luta" (FERNANDES, 1994).

Nesse contexto, a etnogênese surge como estratégia de resistência campesina. Ao resgatar sua identidade indígena, os camponeses do Açaizal evidenciam sua luta em defesa de seu território e, igualmente, de seu modo de vida, buscando transformar sua realidade através da luta por cidadania, na condição de um grupo étnico socialmente organizado. Embora, como afirma Fernandes (2010), a conflitualidade tenha estado sempre presente no território camponês, assim como a identidade indígena do povo Munduruku, o desejo de afirmá-la nasce da necessidade de preservação de seu território, condição indissociável para a reprodução e a defesa da vida.

\section{Considerações Finais}

Com base nas pesquisas empíricas e teóricas desenvolvidas, buscamos analisar os diferentes usos do território na Comunidade Açaizal, bem como o processo de resistência campesina no contexto da expansão do capital agrícola da soja nela estabelecido. Constatamos que a região de Santarém sofre com essa nova realidade, devido a um conjunto de ações públicas e privadas voltadas para a agroindústria, portanto, ligadas ao crescimento da agricultura no país e, consequentemente, de sua economia, com o avanço das exportações de commodities, entre elas a soja.

A territorialização do capital na Amazônia é elemento fundamental para entendermos as dinâmicas do agronegócio da soja na região. A expansão do cultivo em larga escala torna mais complexa a conflitualidade no âmbito da questão agrária, visto estabelecer a convivência 
de dois diferentes sistemas: o agronegócio e o campesinato. Os camponeses da Amazônia são considerados, por parcelas conservadoras, como sinônimo de atraso e de ignorância e, consequentemente, não são ouvidos por parte da sociedade nem por importantes setores do Estado. Tornam-se sujeitos "sem direitos" e, dessa forma, não encontram alternativas para lutar contra as várias formas de expropriação perpetradas pelo capital: a exploração madeireira, a prática da pecuária, ou a expansão da soja.

Como um dos resultados deste estudo, porém, podemos apontar a presença de processos de resistência campesina na Amazônia, especialmente no Pará, em virtude de conflitos pela posse e pelo uso da terra, em decorrência do avanço da territorialidade do capital ligado à expansão agrícola. A etnogênese surge como uma estratégia de resistência, pois, através da ideologia de uma cultura, os atores sociais conseguem se organizar de modo mais eficaz em defesa de seus interesses, como ocorre na Comunidade Açaizal, onde a identidade indígena (Munduruku) é reivindicada, como estratégia para a manutenção de seu território, frente à apropriação do capital, que afeta o desenvolvimento do modo de vida do camponês e, muitas vezes, provoca a sua completa desterritorialização.

Nesse sentido, compreende-se que, na Comunidade Açaizal, o conflito entre camponeses e sojicultores faz parte do processo desigual e contraditório do capitalismo, pois, ao mesmo tempo em que desapropria, provoca como reação a organização dos camponeses para resistir a essa dinâmica de territorialização. No entanto, é interessante lembrar que a etnogênese nasce não como resistência a um determinado conflito - a entrada da soja no território - mas da conflitualidade inerente ao território, um dos aspectos da sociedade, fixo em estrutura, que aguarda o tempo de voltar e as condições políticas de manifestação dos direitos, podendo emergir em diferentes espaços.

$\mathrm{O}$ que ocorre na Comunidade Açaizal, portanto, constitui um arquétipo das várias formas de resistência que se desenvolvem em território santareno. Contudo, como afirma Porto-Gonçalves (2012), a Amazônia possui várias realidades, de forma que os processos sociais e territoriais não se desenvolvem de modo semelhante e variam dependendo do lugar. Cabe ressaltar, todavia, que a apropriação e a subordinação do território são sempre as mesmas, e que o camponês, embora seja sempre também o alvo da opressão de qualquer sociedade conservadora, compreende o processo de luta, visto estar menos sujeito à alienação, ao contrário de outras classes oprimidas. 


\section{Referências Bibliográficas}

ALMEIDA, R. H. C. Identificação dos Atores Sociais e Conflitos Sociais na Fronteira Agrícola da Soja: Comunidade Corta-Corda/Santarém/PA. In: Anais do Congresso de Economia e Sociologia Rural, 2004, Cuiabá. Congresso de Economia e Sociologia Rural, 2004.

ALMEIDA, R. H. Territorialização do campesinato no sudeste do Pará, Belém, 2006.

FABRINI, J. E. . A resistência camponesa para além dos movimento sociais. Revista NERA (UNESP), v. 1, p. 5-22, 2007.

FARIAS, C. S. Manipulação do território: o agronegócio e o campesinato na Amazônia. Campo - Território, v. v. 5, p. 51-70, 2010.

FERNANDES, B. M. Espacialização e territorialização da luta pela terra: a formação do MST Movimento dos Trabalhadores Rurais Sem Terra no Estado de São Paulo. 1994. 208 f. Dissertação (Mestrado em Geografia Humana) - Universidade de São Paulo, USP, São Paulo, 1994.

FERNANDES, B. M. Questão Agrária: conflitualidade e desenvolvimento territorial. In: Sposito, Eliseu Savério; Sant'anna Neto, João Lima. (Org.). Uma Geografia em movimento. São Paulo: Editora Expressão Popular, 2010, v. 1, p. 505-560.

FLORÊNCIO, C. M. D. L. As Margens do Piraquê-Açu: Etnogênese e Território; Uma abordagem Geográfica. 2001. 162 f. Dissertação (Mestrado em Geografia) - Universidade Federal do Espírito Santo, Vitória. 2001.

GAYOSO DA COSTA, S. M. Sojicultura e mercado de terras na amazônia. Revista de Políticas Públicas, v. 19, p. 173-185, 2015.

Territórios e mercado de terras no baixo amazonas-Pará: Expansão da sojicultura e valorização fundiária. In: Anáis da VI Jornada Internacional de Políticas Públicas JOINP, 2013, São Luis. VI JOINP O desenvolvimento da crise capitalista e a atualização das lutas contra a exploração, a dominação e a humilhação. São Luis: UFMA, 2013.

GIRARDI, E. P. Proposição teórico-metodológica de uma Cartografia Geográfica Crítica e sua aplicação no desenvolvimento do Atlas da Questão Agrária Brasileira. 2008. 349 f. Tese (Doutorado em geografia) - Universidade Estadual Paulista Júlio de Mesquita Filho, UNESP, Presidente Prudente, 2008.

MOURA, M. M. Camponeses. 3. ed. São Paulo: Ática, 1988. v. 1.70 p.

OLIVEIRA, A. U. A Geografia Agrária e as transformações territoriais recentes no campo brasileiro. In: Ana Fani Alessandri Carlos. (Org.). Novos caminhos da geografia. São Paulo: Contexto, 2012. p. 87-97.

PEIXOTO, Rodrigo. Indígenas resistentes se movimentam por identidade e território no Baixo Tapajós. In. Anais da VII Conferência da SALSA/Belém - 22 a 26 de junho de 2011.

PORTO-GONÇALVES, C. W. Amazônia, Amazônias. 3. ed. São Paulo: Contexto, 2012.

TEUBAL, M. O campesinato frente à expansão dos agronegócios na América Latina. In: PAULINO, E. T.; FABRINI, J. E. (Org.). Campesinato e territórios em disputa. São Paulo: Editora Expressão Popular, 2008. p. 146.

COSTA, N. M. P.; GOMES, D. M. . (Etno)terminologia na (etno)medicina Mundurukú. In: VII Congresso Internacional da ABRALIN, 2011, Curitiba. Anais do VII Congresso Internacional da ABRALIN, 2011. 
Fundaçao Amazônia. Nova Cartografia Social na Amazônia. < $\underline{\text { http://www.fundoamazonia.gov.br/pt/projeto/Nova-Cartografia-Social-na-Amazonia }>. ~} 2018$.

Recebido em 09 de setembro de 2018. Aceito em 22 de outubro de 2018. 